\title{
Pathological Changes in the Central and Peripheral Nervous System of Young Long-Term Diabetics
}

\author{
The Terminal Neuro-Muscular Apparatus
}

\author{
Edith Reske-Niflsen, Knud Lundbaek, Gunnar Gregersen and Aage Harmsen
}

\begin{abstract}
Department of Neuropathology, Second Clinic of Internal Medicine and Department G of Neurosurgery, Kommunehospitalet, Aarhus University School of Medicine, Aarhus, Denmark
\end{abstract}

Received: September 11, 1969

Summary. Muscle biopsies were studied from sixteen juvenile, long-term diabetics. Most of the patients had severe retinopathy, but clinical signs of other forms of angiopathy and neuropathy were either absent or mild. The biopsies revealed severe degeneration, as well as ineffective regenerative changes of the terminal nerve fibres and endorgans.

Modifications pathologiques dans le système nerveux central et périphérique de sujets jeunes, diabétiques depuis longtemps. L'appareil neuro-musculaire terminal

Résumé. Des biopsies musculaires ont été étudiées chez seize sujets jeunes diabétiques depuis longtemps. La plupart des patients étaient atteints de rétinopathie grave, mais les signes cliniques d'autres formes d'angio. pathie et de neuropathie étaient soit absents, soit légers. Les biopsies ont révélé une dégénérescence grave ainsi que des modifications régénératives inefficaces des fibres nerveuses terminales et des organes terminaux.
Pathologische Veränderungen am zentralen und peripheren Nervensystem von jüngeren Langzeit-Diabetikern. Die neuromuskuläre Endplatte

Zusammenfassung. Es wurden Muskelbiopsien von 16 jüngeren Langzeitdiabetikern untersucht. Die meisten Patienten litten an einer schweren Retinopathie, doch wiesen sie nur schwache oder keine klinischen Anzeichen eines anderen Gefäßleidens oder einer Neuropathie auf. Die Biopsien zeigten schwere degenerative Erscheinungen und außerdem frustrane regenerative Veränderungen der terminalen Nervenfasern und Endorgane.

Key-words: Long-term diabetes, neuropathy, motor endplates, muscle biopsy, neurogenic atrophy, intramuscular nervous system, electromyography, vibration sense, motor conduction velocity.
In two earlier papers of this series we discussed the cerebral pathology (Reske-Nielsen, Lundbæk and Rafaelsen, 1965) and the pathology of the spinal cord and peripheral nerves (Reske-Nielsen and Lundbæk, 1968 ) in young diabetics dying from long-term vascular disease. In the first of these we described the severe abnormalities of the brain, and proposed the designation 'diabetic encephalopathy' for this characteristic histological pattern. The findings in that study have since been confirmed by others (Olsson et al., 1968). In the second paper we discussed the difficult problem of the relationship between vascular abnormalities and nervous system changes in long-term diabetics. The vascular changes observed were mild or absent in the spinal cord, more pronounced in the peripheral nerves, and very severe in the small vessels and capillaries of the muscles. A dual pathogenesis of clinical peripheral neuropathy in diabetes was suggested, viz. a metabolic disturbance of nervous tissue combined with a slowly developing angiopathy.

The present, third and last paper of this series is a report on the terminal neuro-muscular apparatus. In contrast to the two earlier papers this study is not based on autopsy material, but on observations of specifically stained biopsy specimens. As in the earlier papers, however, the emphasis is on the fact that only juvenile diabetics are included, and only patients with many years of duration of diabetes.

\section{Patients and Methods}

The series consists of 16 patients (Table 1). The average age and the duration of diabetes were 29 and 20 years respectively. All of them had diabetic retinopathy, twelve of them severe proliferative retinopathy with blindness or near blindness at least in one eye. Proteinuria was present in seven patients, but only two had elevated serum creatinine. None of the patients had significant hypertension or cardiac complaints.

As can be seen from the table, most of the patients presented deep areflexia, although only three of them had clinical muscle weakness or wasting. In contrast to the autopsy series described earlier (Reske-Nielsen and Lundbæk, 1968), none of the patients had severe and incapacitating neuro-encephalopathic syndromes.

Vibration perception threshold was measured with a thesiometer in all patients but one. Motor conduction velocity was measured and electromyography performed in eight patients.

The muscle biopsies were removed from the short peroneal muscle in eleven patients, the anterior tibial muscle in three and the long palmar muscle in two patients. The localization of the end-plates in these muscles is well-defined.

One piece of biopsy was treated by ordinary histological methods; another stained by Koelles choli- 
Table 1. Clinical and neurophysiological data

Retinopathy: + diabetic retinopathy, ++ proliferative retinopathy, +++ severe proliferative retinopathy. - Visual acuity: h.m. hand movements, f.c. finger count, l.p. light perception. - Nephropathy: $(+)$ slight proteinuria, + more mascive proteinuria or elevated serum creatinine. - Arterial hypertension: $(+)$ diastolic pressure 100 $-110,+$ diastolic pressure more than 110. - X-ray of crura and feet: + slight calcification of vessels, + + pronounced calcification of vessels. - Hypoglycaemic episodes: $(+)$ seldom, + often, ++ numerous. $-M C V:$ motor conduction velocity, normal values about $50 \mathrm{~m} / \mathrm{sec}$. -Vibratory perception threshold: measured with a thesiometer, normal values usually below 10 volts. - EMG: electromyography of the extensor digitorum brevis muscle

\begin{tabular}{|c|c|c|c|c|c|c|c|c|c|c|c|c|c|c|c|c|c|c|c|c|c|}
\hline $\begin{array}{l}\dot{0} \\
z \\
\overrightarrow{0} \\
\overrightarrow{0} \\
.0 \\
0\end{array}$ & $\frac{20}{3}$ & $\begin{array}{r}4 \\
0 \\
0 \\
\end{array}$ & $\sum_{4}^{80}$ & 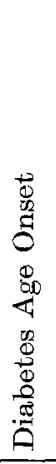 & 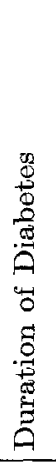 & 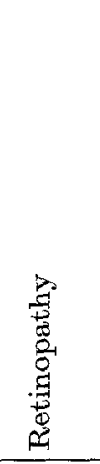 & 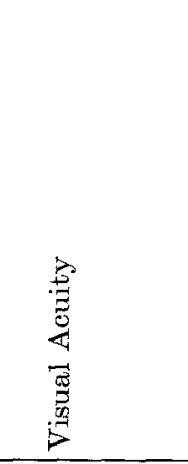 & 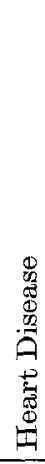 & 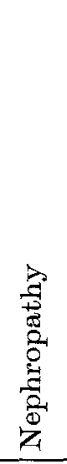 & 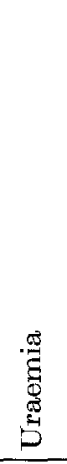 & 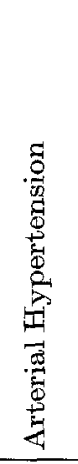 & 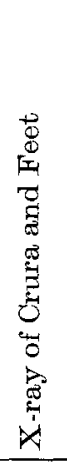 & 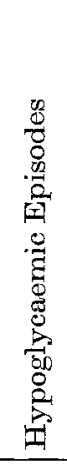 & 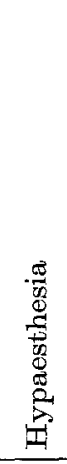 & 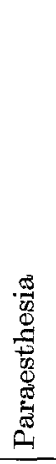 & $\begin{array}{l}\stackrel{9}{7} \\
0 \\
0 \\
0 \\
0\end{array}$ & 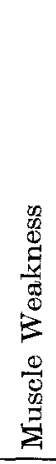 & 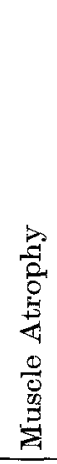 & 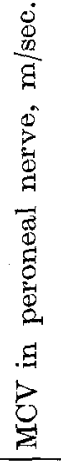 & 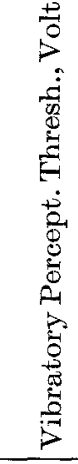 & 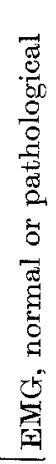 \\
\hline 4168 & $\mathrm{KU}$ & F & 33 & 11 & 22 & $+t+$ & $>0.67 / \mathrm{h} . \mathrm{m}$ & 0 & 0 & 0 & 0 & $t+$ & 0 & 0 & 0 & + & 0 & 0 & & 15 & \\
\hline 4176 & CGN & $\mathrm{M}$ & 37 & 13 & 24 & + & $<0.4 / 0.4$ & 0 & $(+)$ & 0 & 0 & ++ & 0 & + & + & + & 0 & + & $\mathrm{a}$ & $>50$ & $\mathrm{p}$ \\
\hline 4213 & $\mathrm{CF}$ & $\mathbf{M}$ & 31 & 7 & 24 & $t+$ & $0.15 / 0.25$ & 0 & + & 0 & 0 & ++ & 0 & $(+)$ & + & 0 & 0 & 0 & 38 & 13 & $\mathrm{p}$ \\
\hline 5142 & IRS & M & 27 & 20 & 7 & + & $1.0 / 1.0$ & 0 & 0 & 0 & 0 & 0 & 0 & $(+)$ & + & + & + & + & 33 & 18 & $\mathrm{p}$ \\
\hline 5327 & PK & M & 27 & 1 & 26 & ++ & 1.p. $/<1.0$ & 0 & 0 & 0 & 0 & $t+$ & + & 0 & 0 & 0 & 0 & 0 & 37 & 28 & $\mathbf{n}$ \\
\hline 5498 & CEI & M & 32 & 8 & 24 & $+t+$ & f.c. $/ 0.4$ & 0 & $(+)$ & 0 & $(+)$ & 0 & 0 & 0 & + & + & 0 & 0 & & 35 & \\
\hline 5829 & SN & $\mathbf{M}$ & 33 & 2 & 31 & $++t$ & 1.p. $/>1.0$ & 0 & 0 & 0 & 0 & 0 & 0 & 0 & 0 & + & 0 & 0 & & 38 & \\
\hline 5930 & IMBP & $\mathrm{F}$ & 37 & 10 & 27 & +++ & h.m. $/>0.4$ & 0 & + & $(+)$ & $(+)$ & 0 & 0 & + & 0 & + & + & + & 33 & $>50$ & $\mathrm{p}$ \\
\hline 5971 & ISK & $\mathrm{F}$ & 30 & 11 & 19 & $+t+$ & f.c. $/>1.0$ & 0 & 0 & 0 & 0 & 0 & 0 & 0 & 0 & + & 0 & 0 & 45 & 14 & $\mathrm{n}$ \\
\hline 5981 & HES & $\mathbf{F}$ & 20 & 3 & 17 & +++ & f.c. $/>0.2$ & 0 & 0 & 0 & o & + & 0 & 0 & + & 0 & 0 & 0 & 31 & 9 & $\mathrm{p}$ \\
\hline 6211 & KMP & $\mathbf{M}$ & 31 & 8 & 23 & $++\div$ & $0.67 / \mathrm{h} . \mathrm{m}$. & 0 & 0 & 0 & 0 & + & 0 & $(+)$ & 0 & + & 0 & 0 & & 22 & \\
\hline 6239 & EVA & $\mathrm{F}$ & 26 & 11 & 15 & $+t+$ & $0.2 / 0.25$ & 0 & + & + & + & ++ & $(t)$ & 0 & $t$ & + & O & 0 & 33 & 17 & $\mathrm{p}$ \\
\hline 7234 & MDW & $\mathbf{F}$ & 30 & 13 & 17 & +++ & f.c. $/ 0.5$ & 0 & $(+)$ & 0 & 0 & 0 & 0 & 0 & + & + & 0 & 0 & & 11 & \\
\hline 7830 & VN & M & 26 & 11 & 15 & $+t+$ & $0.05 / 0.1$ & 0 & + & 0 & 0 & & 0 & 0 & 0 & + & 0 & 0 & & & \\
\hline 8955 & TI & $\mathrm{F}$ & 29 & 17 & 12 & $++t$ & $0.67 / \mathrm{h} . \mathrm{m}$ & 0 & 0 & 0 & 0 & 0 & $(+)$ & 0 & 0 & + & 0 & 0 & & 38 & \\
\hline 9323 & BM. & $\mathbf{F}$ & 23 & 11 & 12 & +++ & $0.67 / 0.1$ & o & 0 & 0 & 0 & & $(+)$ & 0 & 0 & 0 & 0 & 0 & & 8 & \\
\hline
\end{tabular}

a MCV unmeasurable

Table 2. Histological findings in muscle biopsies

\begin{tabular}{|c|c|c|c|c|c|c|c|c|c|c|}
\hline 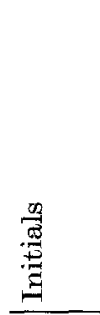 & $\dot{0}$ & 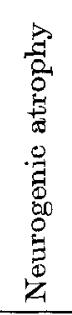 & 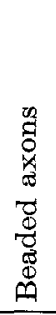 & 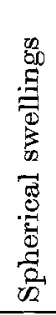 & 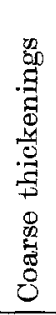 & 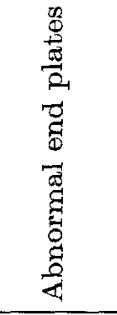 & 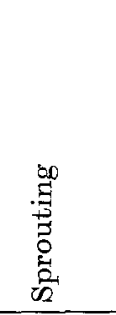 & 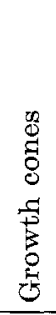 & 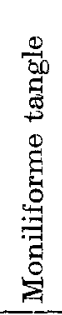 & 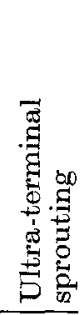 \\
\hline $\mathrm{KU}$ & 4168 & $(+)$ & + & & + & ++ & ++ & + & + & + \\
\hline CGN & 4176 & + & + & & & ++ & ++ & & + & \\
\hline $\mathrm{CF}$ & 4213 & + & + & & + & ++ & ++ & & & \\
\hline IRS & 5142 & + & + & & + & +++ & +++ & & & + \\
\hline PK & 5327 & + & + & + & + & +++ & $++t+$ & + & & + \\
\hline CEI & 5498 & + & + & & + & & $++t$ & & + & + \\
\hline $\mathrm{SN}$ & 5829 & $(+)$ & + & + & + & $++t$ & $+t+$ & + & & \\
\hline IMBP & 5930 & $(+)$ & + & & & ++ & + & & & \\
\hline ISK & 5971 & $(+)$ & + & + & + & $++t$ & +++ & & & \\
\hline $\mathrm{HP}$ & 5981 & $(+)$ & + & & + & $+++t$ & $+++t$ & & & \\
\hline KMP & 6211 & + & + & & & + & $+t+$ & & + & \\
\hline EVA & 6239 & + & + & & + & $+t+t$ & ++++ & + & + & \\
\hline MDW & 7234 & + & + & & & ++ & & & & \\
\hline $\mathrm{VN}$ & 7830 & $(+)$ & + & + & + & $t+$ & ++ & & & \\
\hline TI & 8955 & $(+)$ & + & & + & $+t+$ & +++ & & & \\
\hline $\mathrm{BM}$ & 9323 & $(+)$ & + & + & + & +++ & +++ & + & & \\
\hline
\end{tabular}


nesterase method for visualizing the subneural muscular end-plates; and a third piece of biopsy was stained intravitally with methylene blue (Coërs, 1952; Coërs and Woolf, 1959; Reske-Nielsen et al., 1969) to demonstrate the intramuscular nerve fibres. ing fibres, not to their more or less abnormal appear. ance.

In half of the patients, the microscopic investigation of the ordinary muscle biopsies showed slender muscle fibres, increased number of sarcoplasmic nuclei

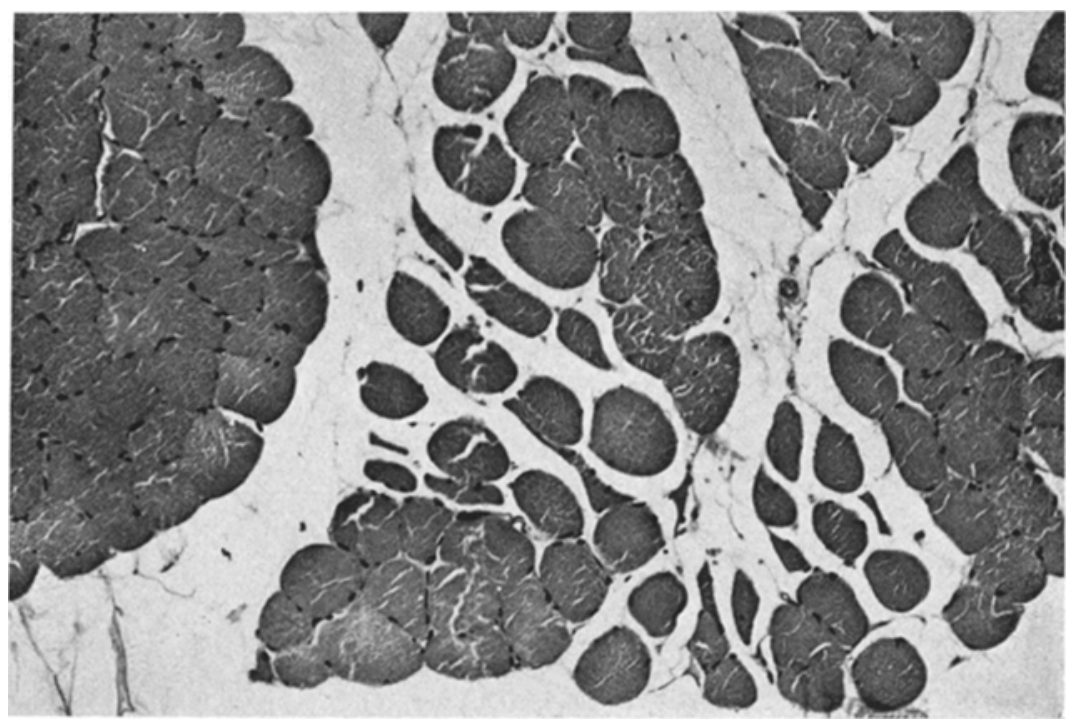

Fig. 1. Transversal section of muscle biopsy with small groups of uniformly atrophied muscle fibres, showing neurogenic atrophy

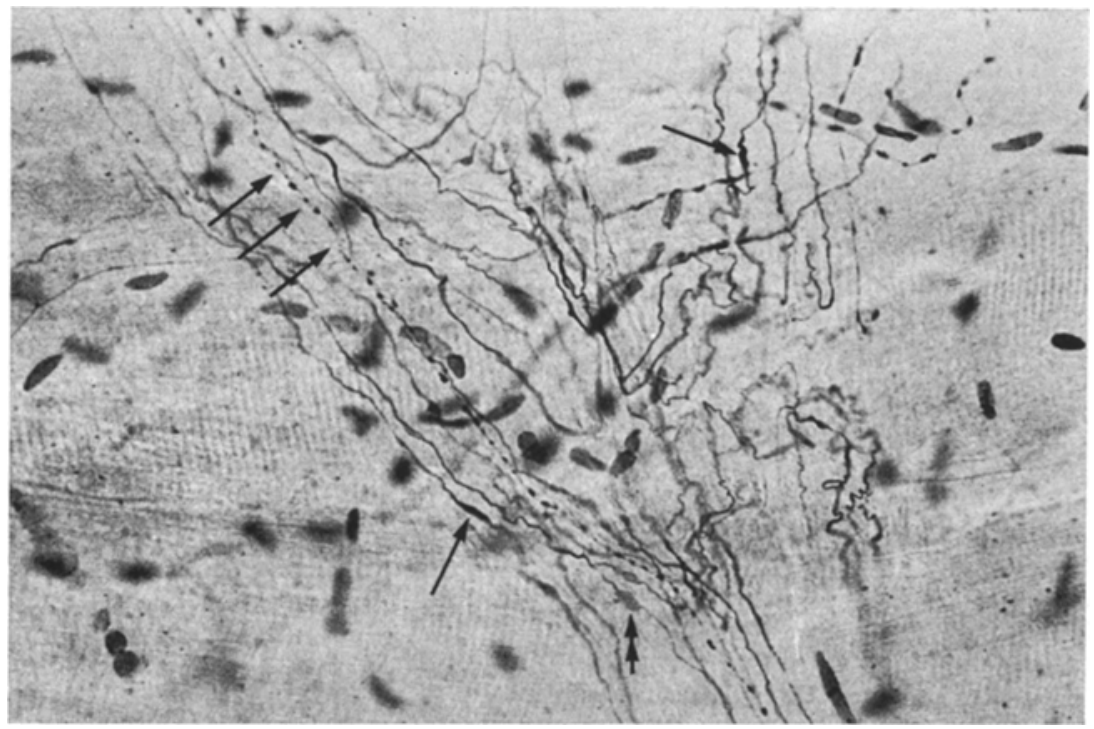

Fig. 2. Intramuscular nerve bundles with beaded axons, (three arrows), thickenings (arrows), and swellings ( $\lambda^{\pi}$ ) of the nerve fibres

\section{Results}

The results obtained are listed in Table 2. Only "abnormal end-plates" and"sprouting" are indicated in a graduated system of plusses. It is important to note that "sprouting" refers to the number of sprout- and fat cells between the fibres indicating incipient neurogenic atrophy. In the other cases small areas of identically atrophied fibres were seen, i. e. fully developed neurogenic atrophy (Fig. 1). Fibres with hyaline degeneration, basophilia and ringed fibres were seen in some cases. 
In three of the 16 cases the muscle capillaries were thickened.

The cholinesterase staining of Koelle revealed more subneural apparatuses than normal, often two or served, whereas others demonstrated degenerative alterations as large spherical axonic swellings, irregular dark thickenings or coarse fragmentations (Figs. 2 and 3).

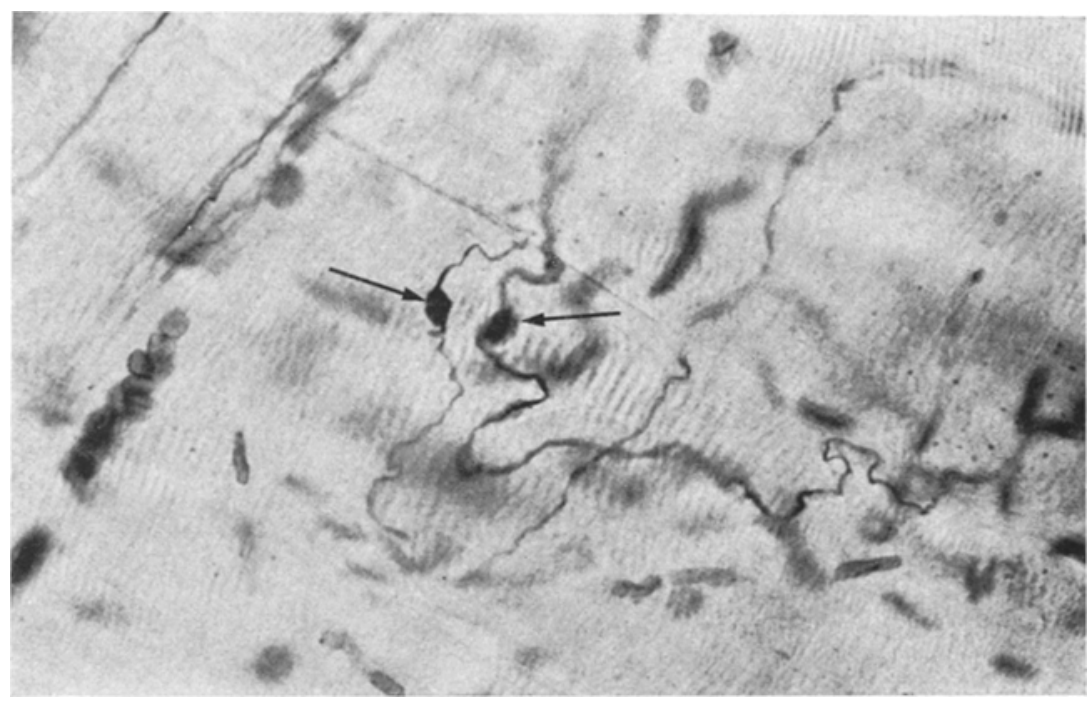

Fig. 3. Terminal axons with spherical swellings" (arrows)

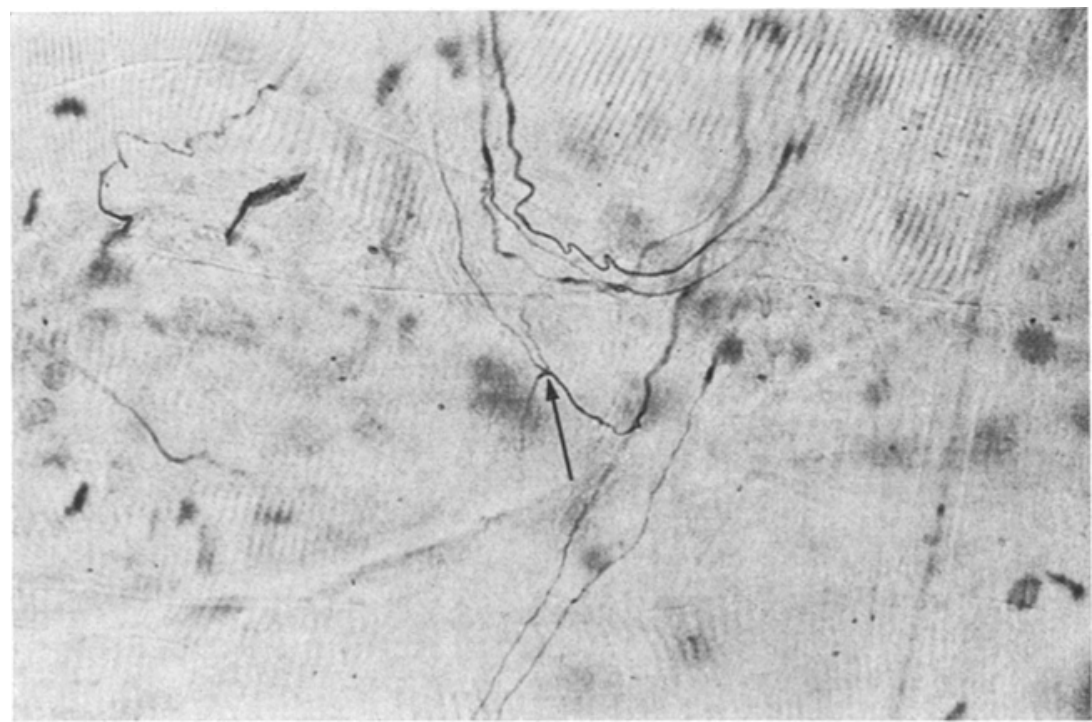

Fig. 4. Three new axons radiating from the same point (arrow)

three on each fibre. Many of these consisted of one or a few big fringed units of normal size and shape, with well laminated and sharply defined borders; other were enlarged and elongated. Very small subneural apparatuses were also seen. Signs of degeneration were pronounced. Many of the apparatuses were fragmented, vacuolized and pale.

The intravital methylene blue preparations revealed nerve bundles with a normal or slightly decreased number of axons. Some of the nerve fibres were well pre-
The subterminal nerve fibres showed the same aiterations, and at the same time they were often varicose and tortuous.

Most of the end-plates were elongated, ring-formed or of bizarre outline, the telodendrions being thicker or thinner than normal. The terminal expansions varied in shape from dark and atrophic to light and globular. Sometimes they formed abnormal club-like swellings.

Corresponding to the degeneration and destruction, 
there were signs of regeneration and production of new axons and nerve end-plates.

There were many divisions in the course of the bundles and the subterminal axons. Many sprouts arose
In some cases a sprouting fibre terminated in a very small, dark homogenous abortive growth cone, and sometimes the fine beaded sprouts formed a moniliform tangle.

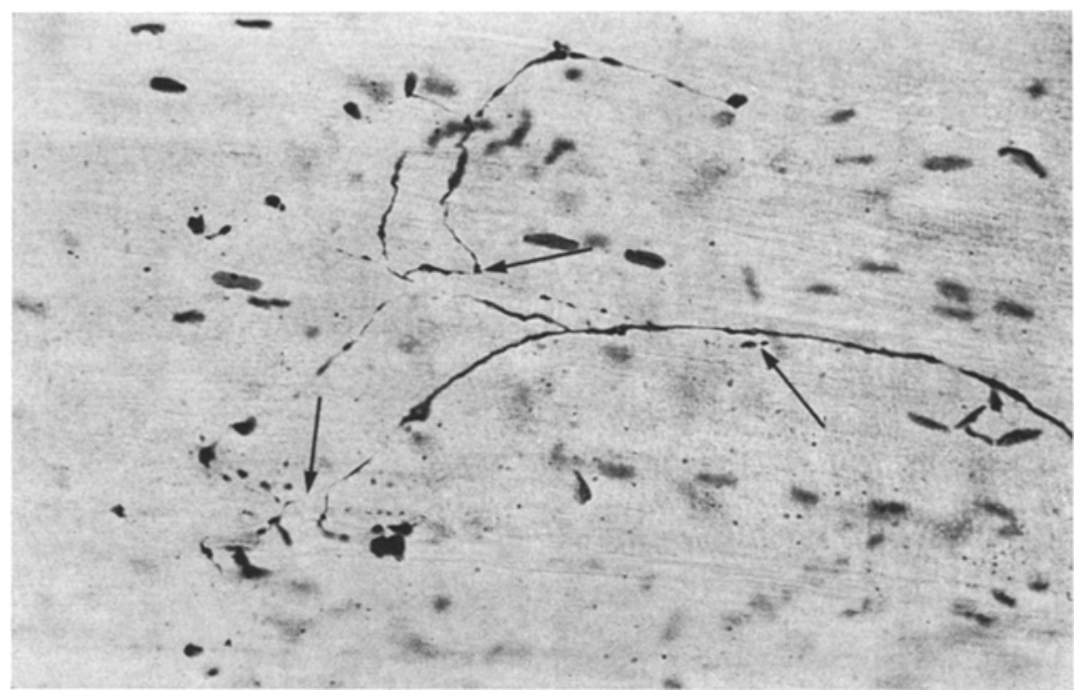

Fig. 5. Axon with numerous new, thin and defective sprouts (arrows)

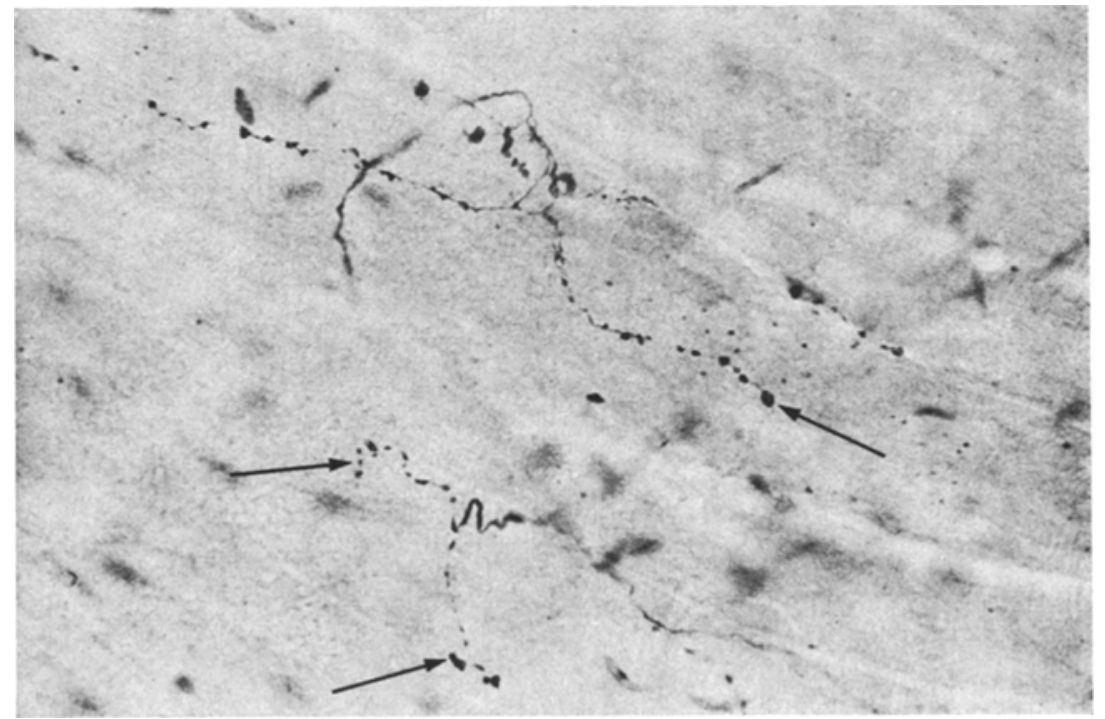

Fig. 6. Abnormal sprouting with small, incomplete end-plates (arrows)

from the subterminal fibres - often near the nerve end-plates - or from one of the terminal expansions of an end-plate.

The new sprouts - three, five or more branches from one subterminal axon - had a special appearance. They were very short and thin, or finely beaded with slender, delicately curved telodendrions and few very small dark terminal expansions (Figs. 4 and 5).

The new-formed nerve end-plates were tiny and faintly developed (Fig. 6).

\section{Discussion}

The intramuscular nervous system and subneural apparatus in diabetes mellitus have been studied before by Woolf and Malins (1957), Coërs and Hildebrand (1965) and Coërs (1966). Their series consisted mainly of elderly patients, and no information was given about the duration or apparent duration of diabetes. Our findings in the present biopsy series from young patients with a well-known long duration of diabetes are, 
however, in accordance with the findings of the above mentioned authors.

The results obtained indicate a severe degeneration of the terminal neuromuscular apparatus in long-term diabetes, with sign of insufficient and abnormal regeneration.

The intramuscular nerve bundles, the subterminal nerve fibres and the end-plates showed degenerative and destructive as well as regenerative changes. There was a very high degree of re-innervation, and the number of neurogenic end-plates seemed to exceed considerably the number of subneural apparatuses. The sprouts of the subterminal axons were very numerous but thin and defective - a characteristic histological feature of the muscle biopsies of this group of young long-term diabetics.

The impression gained was that of an intramuscular nerrous system which has lost its ability to form normal functioning end-plates.

This picture differs from the one observed in cases of recent juvenile diabetes (Reske-Nielsen et al., 1969). In such patients the sprouting is vigorous and healthy looking, and severe degeneration of the subneural apparatus is not observed.

\section{References}

Coërs, C.: The vital staining of muscle biopsies with methylene blue. J. Neurol. Neurosurg. Psychiat. 15, 211-215 (1952).
- Altération neuro-musculaire dans le diabète. Extraits du Compte rendu du Congrès de Psychiatrie et de Neurologie de Langue Française (1966).

- Hildebrand, J.: Latent neuropathy in diabetes and alcoholism. Neurology (Minneap.) 15, 19-38 (1965).

- Woolf, A.L.: The innervation of muscle. A biopsy study. Oxford: Blackwell 1959.

Olsson, Y., Säve-Söderbergh, J., Sourander, P., Angervall, L.: A patho-anatomical study of the central and peripheral nervous system in diabetes of early onset and long duration. Path. europ. 3, 62-79 (1968).

Rəske-Nielsen, E., Harmsen, Aa., Hejgaard, J.J.: Modified technique of muscle biopsy. Acta path. microbiol. scand. 1969. In press.

- Gregersen, G., Harmsen, Aa., Lundbæk, K.: Morphological abnormalities of the terminal neuromuscular apparatus in recent juvenile diabetes. Diabetologia 6, $104-109(1970)$.

- Lundbæk, K.: Pathological changes in the central and paripheral nervous system of young long-term diabetics. II. The spinal cord and peripheral nerves. Diabetologia 4, 34-43 (1968).

- Lundbæk, K., Rafaelsen, O.J.: Pathological changes in the central and peripheral nervous system of young long-term diabetics. I. Diabetic encephalopathy. Diabetologia 1, 233-241 (1965).

Woolf, A.L., Malins, J.M.: Changes in the intramuscular nerve endings in diabetic neuropathy; a biopsy study. J. Path. Bact. 73, 316-318 (1957).

E. Reske-Nielsen

Kommunehospitalet

Aarhus University School of Medicine

Aarhus, Denmark 